The University of Southern Mississippi The Aquila Digital Community

Faculty Publications

6-1-2011

\title{
Differential Gene Expression of FoxO1, ID 1, and ID3 Between Young and Older Men and Associations With Muscle Mass and Function
}

Thomas W. Buford

University of Florida, tbuford@ufl.edu

Matthew B. Cooke

University of Queensland, matt.cooke@vu.edu.au

Brian D. Shelmadine

Baylor University

Geoffrey M. Hudson

University of Southern Mississippi, ghudson2@gwu.edu

Liz L. Redd

Baylor University

See next page for additional authors

Follow this and additional works at: https://aquila.usm.edu/fac_pubs

Part of the Sports Medicine Commons

\section{Recommended Citation}

Buford, T. W., Cooke, M. B., Shelmadine, B. D., Hudson, G. M., Redd, L. L., Willoughby, D. S. (2011). Differential Gene Expression of FoxO1, ID1, and ID3 Between Young and Older Men and Associations With Muscle Mass and Function. Aging Clinical and Experimental Research, 23(3), 170-174.

Available at: https://aquila.usm.edu/fac_pubs/440

This Article is brought to you for free and open access by The Aquila Digital Community. It has been accepted for inclusion in Faculty Publications by an authorized administrator of The Aquila Digital Community. For more information, please contact Joshua.Cromwell@usm.edu. 
Authors

Thomas W. Buford, Matthew B. Cooke, Brian D. Shelmadine, Geoffrey M. Hudson, Liz L. Redd, and Darryn S. Willoughby 
Published in final edited form as:

Aging Clin Exp Res. 2011 June ; 23(3): 170-174.

\title{
Differential gene expression of Fox01, ID1, and ID3 between young and older men and associations with muscle mass and function
}

\author{
Thomas W. Buford ${ }^{1}$, Matthew B. Cooke ${ }^{2}$, Brian D. Shelmadine ${ }^{3}$, Geoffrey M. Hudson ${ }^{4}$, Liz \\ L. Redd ${ }^{3}$, and Darryn S. Willoughby ${ }^{3}$ \\ ${ }^{1}$ Department of Aging and Geriatric Research, University of Florida, Gainesville, FL, USA \\ ${ }^{2}$ Schools of Medicine and Human Movement Studies, University of Queensland, Queensland, \\ Australia \\ ${ }^{3}$ Department of Health, Human Performance and Recreation, Baylor University, Waco, TX, USA \\ ${ }^{4}$ School of Human Performance and Recreation, University of Southern Mississippi, Hattiesburg, \\ MS, USA
}

\section{Abstract}

Background and aims-Aging is associated with significant losses of skeletal muscle mass and function. Numerous biochemical molecules have been implicated in the development of these age-related changes, however evidence from human models is sparse. Assessment of transcript expression is useful as it requires minimal tissue and may potentially be used in clinical trials. This study aimed to compare mRNA expression of proteolytic genes in skeletal muscle of young (1835 yrs) and older (55-75 yrs) men.

Methods-Muscle tissue was obtained from young ( $\mathrm{n}=14,21.35 \pm 1.03$ yrs) and older $(\mathrm{n}=13$, $63.85 \pm 1.83$ yrs) men using percutaneous biopsy, and transcript expression was quantified using real-time polymerase chain reaction. Lower limb muscle mass was assessed using DEXA while concentric peak torque (PT) and power were assessed via isokinetic dynamometer. When agerelated differences in mRNA expression were observed, Pearson correlation coefficients were obtained to examine the relationship of transcripts to muscle mass and function.

Results-Older muscle contained significantly more transcript for Forkhead Box O 1 (FoxO1, $p=0.001$ ), Inhibitor of DNA binding 1 (ID1, $p=0.009$ ), and Inhibitor of DNA Binding 3 (ID3, $p=0.043)$ than young muscle. FoxO1 was significantly correlated with lean mass $(\mathrm{R}=-0.44$, $p=0.023)$ and $\mathrm{PT}(\mathrm{R}=-0.40, p=0.046)$ while ID3 was significantly correlated with $\mathrm{PT}(\mathrm{R}=-0.58$, $p=0.001)$ and power $(\mathrm{R}=-0.65, p<0.001)$. Moreover, ID1 was significantly correlated with all assessed measures of muscle function - mass $(\mathrm{R}=-0.39, p=0.046), \mathrm{PT}(\mathrm{R}=-0.53, p=0.005)$, and power $(\mathrm{R}=-0.520, p=0.005)$.

Conclusion-These data suggest that FoxO1, ID1, and ID3 are potentially useful as clinical biomarkers of age-related muscle atrophy and dysfunction.

\section{Keywords}

Aging; atrophy; peak torque; proteolysis; RNA; sarcopenia 


\section{INTRODUCTION}

Sarcopenia, the age-related loss of muscle mass and quality, is a major healthcare concern for older adults. The condition is a primary contributor to declines in muscle function and the development of disability $(1,2)$. As a consequence of such disability, many older persons are unable to remain fully independent in carrying out their daily activities. Because of the costs associated with caring for an individual with compromised function, sarcopenia is also an important contributor to escalating healthcare costs. Moreover, the absolute costs associated with sarcopenia are likely to rise sharply in the coming decades considering that the total number of persons over 65 years is expected to double over the next 25 years (3). Hence, additional knowledge of mechanisms underlying sarcopenia development is necessary to advance prevention and treatment efforts that will improve the quality of life for millions of older adults.

A number of cellular mechanisms are known to contribute to skeletal muscle atrophy, of which those contributing to myofibrillar protein breakdown are among the best described. These mechanisms include the ubiquitin-proteasome system (4-6), calcium-activated proteases (calpains) (7-9), myostatin (10-12), and inhibitors of DNA binding (IDs) (13-15). Upregulation of these regulators contributes to the loss of myofibrillar protein by either active proteolysis (ubiquitin-proteasome and calpains) or through the repression of anabolic signaling (myostatin and IDs).

Despite the availability of extensive mechanistic data regarding these systems, translational studies demonstrating relationships of these biochemical indices to clinical measures of muscle mass and force production are few. Moreover, these few published results are somewhat equivocal regarding age-dependent differences in skeletal muscle expression of transcripts relevant to loss myofibrillar protein. Indeed, previous studies have indicated either increases or no change with increasing age in muscle content of mRNA encoding for proteins such as myostatin $(16,17)$, muscle-specific ring finger 1 (MuRF1) (17-19) and forkhead box O 3A (FoxO3A) $(17,19,20)$. Thus, the objective of this investigation was to analyze relevant transcript expression between young and older men and to test the hypothesis that differentially-expressed mRNA are associated with clinical measures of muscle mass and function.

\section{METHODS}

Data are from young and older healthy men who volunteered for the study. Inclusion/ exclusion criteria are detailed elsewhere (21). Briefly, men 1) were between either 18-30 or 55-75 years, 2) had a physically sedentary lifestyle (reported no regular physical activity beyond light walking in past year), 3) did not smoke, and 4) were not currently receiving or had not recently completed (within 6 months) androgen therapy. All participants provided oral and written informed consent based on documents approved by the Institutional Review Board of Baylor University according to the principles of the Declaration of Helsinki.

Body mass, heart rate, and blood pressure were determined by standard procedures. Body composition was assessed using dual energy x-ray absorptiometry (DEXA) (Hologic, Waltham, MA). Lean mass was recorded as $\mathrm{g} / \mathrm{cm}^{2}$ in the lower limbs. Isokinetic muscle function of the quadriceps extensors was assessed using a Biodex-System 3 dynamometer (Biodex Medical Systems, Inc., Shirley, NY, USA). On a separate visit prior to data collection, participants were familiarized to the tests to be completed. During data collection, three submaximal and two maximal practice repetitions were completed with the non-dominant limb prior to performing five maximal concentric contractions at 60 degrees/ second with a $75^{\circ}$ range of motion. Peak torque (PT) and peak muscular power were 
recorded for the bout. Skeletal muscle biopsies were obtained under local anesthesia of $1 \%$ Xylocaine from middle portion of the vastus lateralis muscle of the dominant limb at the midpoint between the patella and the greater trochanter of the femur at a depth between 2-3 $\mathrm{cm}$. After removal, tissue samples were immediately frozen in liquid nitrogen and then stored at $-80^{\circ} \mathrm{C}$ for future analyses.

Real-time polymerase chain reaction (RT-PCR) procedures were conducted as previously described $(22,23)$. Briefly, 1) total RNA was isolated from muscle using TRI-reagent (Sigma Chemical Co., St. Louis, MO), 2) cDNA was synthesized using the iScript cDNA Synthesis Kit (Bio-Rad, Hercules, CA), 3) sense and anti-sense primers for target genes and $\beta$-actin control were synthesized commercially (Integrated DNA Technologies, Coralville, IA), and 4) RT-PCR was performed using the iCycler IQ Real-Time PCR Detection System (Bio-Rad, Hercules, CA). The quantity of target gene mRNA was determined relative to the expression of $\beta$-actin using the formula $2^{-\Delta \mathrm{CT}}$ where $\Delta \mathrm{CT}=\mathrm{CT}$ target $-\mathrm{CT} \beta$-actin as previously reported in the literature $(19,24)$.

Data were initially analyzed for normality, homogeneity of variance, and potential outliers prior to determining descriptive statistics. Because of the frequency of assumptions violations, gene expression data for the groups were compared using the non-parametric Mann-Whitney U test. For all other data, groups were compared using independent Student $t$-tests. Pearson correlation coefficients were calculated to examine the relationships among muscle mass, function, and differentially-expressed transcripts. All statistical procedures were performed using SPSS 16.0 software (Chicago, IL) and a probability level of $<0.05$ was adopted throughout.

\section{RESULTS}

In the present study, we obtained biopsy samples from 14 young (21.35 \pm 1.03 yrs) and 13 older $(63.85 \pm 1.83 \mathrm{yrs})$ men. The older group had a significantly greater body mass $(\mathrm{p}=0.036)$ and body fat percentage $p(<0.001)$ than the young group (Table 1$)$. The young group also displayed significantly greater lean mass $(p=0.004)$, PT $(p=0.004)$, and muscular power $(p=0.011)$ than older counterparts.

Expression of all target genes was higher in the older group, although the majority of these differences did not reach significance (Table 1). However, older muscle demonstrated significantly greater expression of mRNA for FoxO1 ( $p=0.001)$, ID1 ( $p=0.009)$, and ID3 $(p=0.043)$ than did younger muscle (Figs. 1-3). Examination of the relationships of these mRNA with muscle mass showed that muscle mass was significantly and inversely correlated with expression of FoxO1 $(\mathrm{R}=-0.44, p=0.023)$ and ID1 $(\mathrm{R}=-0.39, p=0.046)$. The correlations of ID1 $(\mathrm{R}=-0.520, p=0.005)$ and ID3 ( $\mathrm{R}=-0.65, p<0.001)$, but not FoxO1, were significantly correlated with muscle power. Finally, PT was significantly and inversely correlated with all three of the differentially expressed mRNA (FoxO1: $\mathrm{R}=-0.40, p=0.038$; ID1: $\mathrm{R}=-0.53, p=0.005$; ID3: $\mathrm{R}=-0.58, p=0.001$ ).

\section{DISCUSSION}

The present study shows that skeletal muscle gene expression of FoxO1, ID1, and ID3 is significantly greater in older men than younger counterparts. To our knowledge, this is the first investigation to demonstrate age-related differences in these transcripts in humans. Furthermore, this is the first study to report that expressions of these differentially-expressed transcripts are associated with clinical indices of skeletal muscle mass and function.

FoxO is a family of transcription factors that has been implicated in the development of skeletal muscle atrophy through the ubiquitin-proteasome system $(25,26)$. Within skeletal 
muscle, FoxO family members signal increases in ubiquitin-proteasome-mediated proteolysis by up-regulation of muscle specific E3 ligases, including MuRF1 and muscle atrophy F box (MAFbx/Atrogin1) (25). Furthermore, FoxO members also appear to play a role in lysosomal autophagy $(26,27)$ and may also regulate the expression of myostatin $(28)$. To our knowledge, no published studies have reported age-related increases in gene expression of FoxO1 in humans. Previous investigations have however indicated that mRNA expression of FoxO3A is either elevated $(19,20)$ or unchanged (17) in sedentary older individuals. The present data concur with the latter finding as we did not observe significant differences in FoxO3A expression between groups. Further study is needed to clarify the nature of this discrepancy. We suspect that the strong up-regulation of FoxO1 may play some role in ameliorating changes in FoxO3A, but more investigation is certainly required to address this speculation.

Interestingly, despite the presence of significantly greater FoxO1 transcript in older muscle, no significant difference was observed between groups for either MurF1 or Atrogin1. Our findings are intriguing as these FoxO family members are most often ascribed the function of acting on these atrogenes. Several options thus exist for the potential role of FoxO1 in human muscle. First, the lack of group differences for the atrogenes could suggest that FoxO1 may be acting primarily through autophagic mechanisms. Second, because a weak trend was observed between groups for MuRF1, one could speculate that a larger sample size would reveal a significant difference in MuRF1 and that this difference is mediated by FoxO1. This possibility appears plausible despite the striking similarity in Atrogin1 mRNA as accumulating evidence suggests that these two ubiqutin-ligases are regulated in distinct, independent manners (29). However, this potential difference in MuRF1 could also stem from age-dependent increases in NF-kB signaling (21) as NF-kB signals MuRF1 activation $(30,31)$. Much work remains to be done in elucidating the complexity of these signaling pathways in humans.

In addition to the age-related increase in FoxO1 gene expression, we also observed significant increases in ID family members 1 and 3 with no significant difference observed for ID2. At present, little information exists to indicate what molecular differences may regulate ID1 and ID3 differently than ID2 in human muscle during the aging process. IDs are basic helix-loop-helix proteins that act as negative regulators of myogenic regulatory factors (MRFs) by preventing the initiation of transcription by forming MRF-ID heterodimers that are unable to bind to $\mathrm{E}$ boxes because they lack a DNA binding region $(13,32)$. Controlled expression of IDs is critical for maintenance of muscle mass as they are critical repressors of satellite cell differentiation $(15,33)$ and may contribute to apoptosis of myonuclei (13). Previously, Alway et al. (14) reported that ID mRNA levels were $~ 300-$ $900 \%$ higher in skeletal muscle from old rats as compared to young; however this is the first study to report age-related increases in ID expression in humans. Future studies should examine not only ID expression in conjunction with aging, but that of the associated MRFs to determine which of these anabolic signals is most targeted by the IDs in older humans.

Several caveats should be noted to interpret the results of this study. First, the results may not be applicable to women as only men were included in the study. Second, due to its crosssectional nature, this study is not able to determine if skeletal muscle expression of these genes causes declines in skeletal muscle atrophy and/or function. Finally, many other mechanisms, including alterations in cellular signaling of anabolism and satellite cell proliferation, likely contribute to age-related changes in muscle mass and function. As such, this investigation represents but a small step in delineating potential signals of muscle dysfunction in humans. Still, this study is the first to report elevated gene expression of FoxO1, ID1, and ID3 in older men and associations of these mRNA with clinical measures 
of muscle mass and function. Although further study is needed, these indices may represent clinically-relevant signals of potential muscle dysfunction in advanced age.

\section{Acknowledgments}

This study was supported by a doctoral student grant award to TB from Baylor University and by the Baylor University Young Investigator Development Program [Award \#030153134 (MC)]. TB is currently supported by the Office of the Director, National Institutes of Health (1KL2RR029888-01) and the UF Claude D. Pepper Older Americans Independence Center (1P30AG028740).

\section{References}

1. Newman AB, Kupelian V, Visser M, et al. Strength, but not muscle mass, is associated with mortality in the health, aging and body composition study cohort. J Gerontol A Biol Sci Med Sci. 2006; 61:72-7. [PubMed: 16456196]

2. Visser M, Goodpaster BH, Kritchevsky SB, et al. Muscle mass, muscle strength, and muscle fat infiltration as predictors of incident mobility limitations in well-functioning older persons. $\mathrm{J}$ Gerontol A Biol Sci Med Sci. 2005; 60:324-33. [PubMed: 15860469]

3. Federal Interagency Forum on Aging-Related Statistics. Statistical Data of Older Americans. [www.agingstats.gov]

4. de Palma L, Marinelli M, Pavan M, Orazi A. Ubiquitin ligases MuRF1 and MAFbx in human skeletal muscle atrophy. Joint Bone Spine. 2008; 75:53-7. [PubMed: 17977773]

5. Cao PR, Kim HJ, Lecker SH. Ubiquitin-protein ligases in muscle wasting. Int J Biochem Cell Biol. 2005; 37:2088-97. [PubMed: 16125112]

6. Attaix D, Ventadour S, Codran A, Bechet D, Taillandier D, Combaret L. The ubiquitin-proteasome system and skeletal muscle wasting. Essays Biochem. 2005; 41:173-86. [PubMed: 16250905]

7. Huang J, Forsberg NE. Role of calpain in skeletal-muscle protein degradation. Proc Natl Acad Sci USA. 1998; 95:12100-5. [PubMed: 9770446]

8. Costelli P, Reffo P, Penna F, Autelli R, Bonelli G, Baccino FM. Ca(2+)-dependent proteolysis in muscle wasting. Int J Biochem Cell Biol. 2005; 37:2134-46. [PubMed: 15893952]

9. Dargelos E, Brule C, Combaret L, et al. Involvement of the calcium-dependent proteolytic system in skeletal muscle aging. Exp Gerontol. 2007; 42:1088-98. [PubMed: 17937979]

10. Gilson H, Schakman O, Combaret L, et al. Myostatin gene deletion prevents glucocorticoidinduced muscle atrophy. Endocrinology. 2007; 148:452-60. [PubMed: 17038559]

11. Baumann AP, Ibebunjo C, Grasser WA, Paralkar VM. Myostatin expression in age and denervation-induced skeletal muscle atrophy. J Musculoskelet Neuronal Interact. 2003; 3:8-16. [PubMed: 15758361]

12. McCroskery S, Thomas M, Maxwell L, Sharma M, Kambadur R. Myostatin negatively regulates satellite cell activation and self-renewal. J Cell Biol. 2003; 162:1135-47. [PubMed: 12963705]

13. Alway SE, Degens H, Krishnamurthy G, Smith CA. Potential role for Id myogenic repressors in apoptosis and attenuation of hypertrophy in muscles of aged rats. Am J Physiol Cell Physiol. 2002; 283:C66-76. [PubMed: 12055074]

14. Alway SE, Degens H, Lowe DA, Krishnamurthy G. Increased myogenic repressor Id mRNA and protein levels in hindlimb muscles of aged rats. Am J Physiol Regul Integr Comp Physiol. 2002; 282:R411-22. [PubMed: 11792650]

15. Sun L, Trausch-Azar JS, Muglia LJ, Schwartz AL. Glucocorticoids differentially regulate degradation of MyoD and Id1 by N-terminal ubiquitination to promote muscle protein catabolism. Proc Natl Acad Sci USA. 2008; 105:3339-44. [PubMed: 18296633]

16. Leger B, Derave W, De Bock K, Hespel P, Russell AP. Human sarcopenia reveals an increase in SOCS-3 and myostatin and a reduced efficiency of akt phosphorylation. Rejuvenation Res. 2008; 11:163-75B. [PubMed: 18240972]

17. Williamson DL, Raue U, Slivka DR, Trappe S. Resistance exercise, skeletal muscle FOXO3A, and 85-year-old women. J Gerontol A Biol Sci Med Sci. 2010; 65:335-43. [PubMed: 20139145] 
18. Whitman SA, Wacker MJ, Richmond SR, Godard MP. Contributions of the ubiquitin-proteasome pathway and apoptosis to human skeletal muscle wasting with age. Pflugers Arch. 2005; 450:43746. [PubMed: 15952031]

19. Raue U, Slivka D, Jemiolo B, Hollon C, Trappe S. Proteolytic gene expression differs at rest and after resistance exercise between young and old women. J Gerontol A Biol Sci Med Sci. 2007; 62:1407-12. [PubMed: 18166693]

20. Giresi PG, Stevenson EJ, Theilhaber J, et al. Identification of a molecular signature of sarcopenia. Physiol Genomics. 2005; 21:253-63. [PubMed: 15687482]

21. Buford TW, Cooke MB, Manini TM, Leeuwenburgh C, Willoughby DS. Effects of age and sedentary lifestyle on skeletal muscle NF-\{kappa\}B signaling in men. J Gerontol A Biol Sci Med Sci. 2010; 65:532-7. [PubMed: 20045871]

22. Buford TW, Cooke MB, Shelmadine BD, Hudson GM, Redd L, Willoughby DS. Effects of eccentric treadmill exercise on inflammatory gene expression in human skeletal muscle. Appl Physiol Nutr Metab. 2009; 34:745-53. [PubMed: 19767811]

23. Buford TW, Cooke MB, Willoughby DS. Resistance exercise-induced changes of inflammatory gene expression within human skeletal muscle. Eur J Appl Physiol. 2009; 107:463-71. [PubMed: 19669788]

24. Livak KJ, Schmittgen TD. Analysis of relative gene expression data using real-time quantitative PCR and the 2(-delta delta C(T)) method. Methods. 2001; 25:402-8. [PubMed: 11846609]

25. Sandri M, Sandri C, Gilbert A, et al. FoxO transcription factors induce the atrophy-related ubiquitin ligase atrogin-1 and cause skeletal muscle atrophy. Cell. 2004; 117:399-412. [PubMed: 15109499]

26. Zhao J, Brault JJ, Schild A, et al. FoxO3 coordinately activates protein degradation by the autophagic/lysosomal and proteasomal pathways in atrophying muscle cells. Cell Metab. 2007; 6:472-83. [PubMed: 18054316]

27. Zhao J, Brault JJ, Schild A, Goldberg AL. Coordinate activation of autophagy and the proteasome pathway by FoxO transcription factor. Autophagy. 2008; 4:378-80. [PubMed: 18227643]

28. Allen DL, Unterman TG. Regulation of myostatin expression and myoblast differentiation by FoxO and SMAD transcription factors. Am J Physiol Cell Physiol. 2007; 292:C188-99. [PubMed: 16885393]

29. Attaix D, Baracos VE. MAFbx/Atrogin-1 expression is a poor index of muscle proteolysis. Curr Opin Clin Nutr Metab Care. 2010; 13:223-4. [PubMed: 20393275]

30. Cai D, Frantz JD, Tawa NE Jr, et al. IKKbeta/NF-kappaB activation causes severe muscle wasting in mice. Cell. 2004; 119:285-98. [PubMed: 15479644]

31. Mourkioti F, Kratsios P, Luedde T, et al. Targeted ablation of IKK2 improves skeletal muscle strength, maintains mass, and promotes regeneration. J Clin Invest. 2006; 116:2945-54. [PubMed: 17080195]

32. Navarro M, Valentinis B, Belletti B, Romano G, Reiss K, Baserga R. Regulation of Id2 gene expression by the type 1 IGF receptor and the insulin receptor substrate-1. Endocrinology. 2001; 142:5149-57. [PubMed: 11713209]

33. Kumar D, Shadrach JL, Wagers AJ, Lassar AB. Id3 is a direct transcriptional target of Pax7 in quiescent satellite cells. Mol Biol Cell. 2009; 20:3170-7. [PubMed: 19458195] 


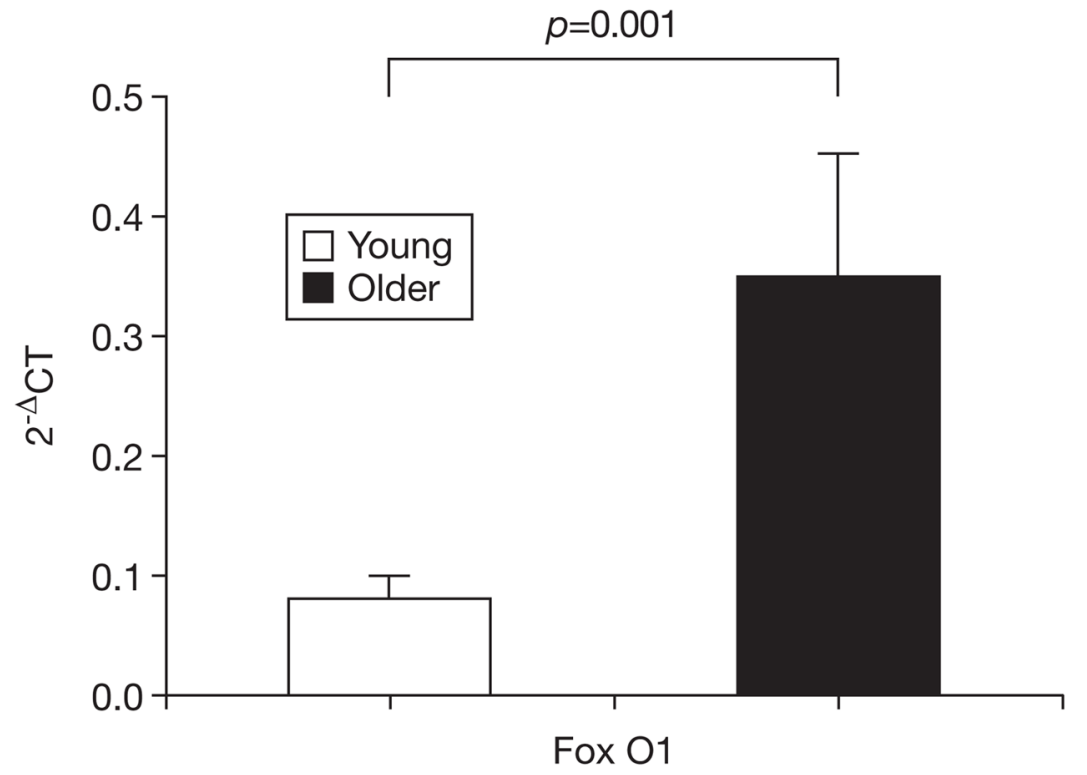

Fig. 1.

mRNA expression of FoxO1 in young and older men. Gene expression expressed relative to $\beta$-actin according to $2^{-\Delta \mathrm{CT}}$ where $\Delta \mathrm{CT}=\mathrm{CT}$ target $-\mathrm{CT} \beta$-actin. Bars depict means, error bars reflect standard error. 


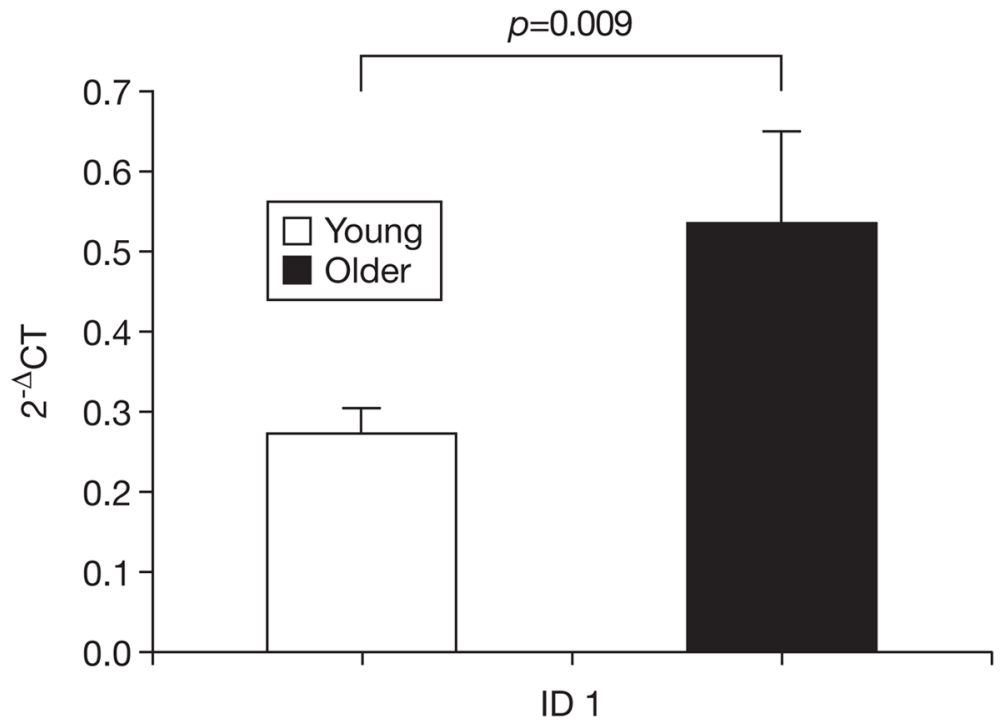

Fig. 2.

mRNA expression of ID1 in young and older men. Gene expression expressed relative to $\beta$ actin according to $2^{-\Delta \mathrm{CT}}$ where $\Delta \mathrm{CT}=\mathrm{CT}$ target $-\mathrm{CT} \beta$-actin. Bars depict means, error bars reflect standard error. 


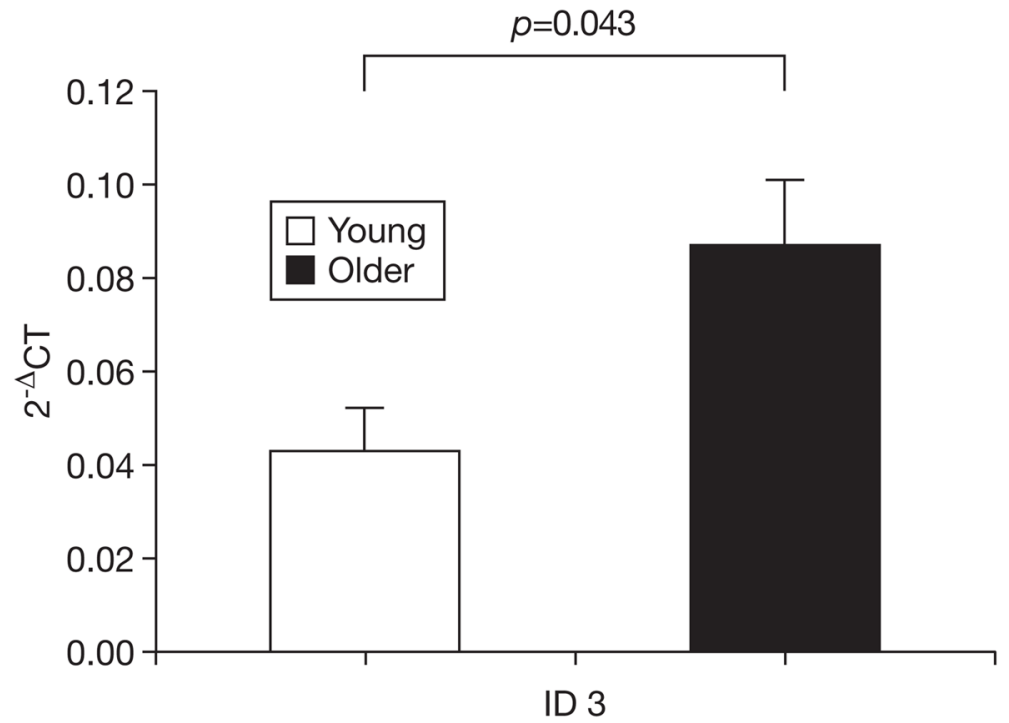

Fig. 3.

mRNA expression of ID3 in young and older men. Gene expression expressed relative to $\beta$ actin according to $2^{-\Delta \mathrm{CT}}$ where $\Delta \mathrm{CT}=\mathrm{CT}$ target $-\mathrm{CT} \beta$-actin. Bars depict means, error bars reflect standard error. 


\section{Table 1}

Physical characteristics, body composition, muscle function, and muscle expression of atrophy-related genes.

\begin{tabular}{lccc}
\hline & Young $(\mathbf{n = 1 4})$ & Older $(\mathbf{n}=\mathbf{1 3})$ & $\boldsymbol{p}$-value \\
\hline Height $(\mathrm{cm})$ & $176.8 \pm 1.6$ & $174.0 \pm 1.7$ & 0.225 \\
Body mass $(\mathrm{kg})$ & $79.6 \pm 4.6^{*}$ & $93.7 \pm 4.2^{*}$ & 0.036 \\
Body fat \% & $21.0 \pm 2.1^{*}$ & $31.7 \pm 1.2^{*}$ & $<0.001$ \\
Lower limb lean mass $\left(\mathrm{g} / \mathrm{cm}^{2}\right)$ & $24.9 \pm 0.7^{*}$ & $22.0 \pm 0.6^{*}$ & 0.004 \\
Quadriceps peak torque $(\mathrm{Nm})$ & $149.6 \pm 7.1^{*}$ & $115.3 \pm 8.5^{*}$ & 0.004 \\
Quadriceps power $(\mathrm{W})$ & $94.9 \pm 7.0^{*}$ & $67.6 \pm 7.1^{*}$ & 0.011 \\
Muscle gene expression ${ }^{a}$ & & & \\
MuRF 1 & $0.32 \pm 0.66$ & $0.84 \pm 0.30$ & 0.089 \\
Atrogin 1 & $14.84 \pm 5.67$ & $16.55 \pm 4.29$ & 0.356 \\
FoxO3A & $0.41 \pm 0.09$ & $1.09 \pm 0.53$ & 0.451 \\
Calpain 1 & $1.14 \pm 0.23$ & $2.12 \pm 0.58$ & 0.065 \\
Calpain 2 & $1.22 \pm 0.29$ & $3.01 \pm 1.56$ & 0.527 \\
Myostatin & $0.59 \pm 0.12$ & $1.83 \pm 0.85$ & 0.650 \\
ID2 & $0.28 \pm 0.05$ & $0.41 \pm 0.12$ & 0.771 \\
\hline
\end{tabular}

Values are means \pm SE.

* $<<0.05$ significantly different between groups.

${ }^{a}$ All gene expression values expressed relative to $\beta$-actin according to $2^{-\Delta \mathrm{CT}}$ where $\Delta \mathrm{CT}=\mathrm{CT}$ target $-\mathrm{CT} \beta$-actin. 